\title{
Berberine Supplement and Resistance Training May Ameliorate Diazinon Induced Neural Toxicity in Rat Hippocampus Via the Activation of the TrkB and ERK Signaling Pathway
}

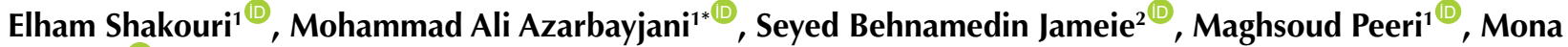 \\ Farhadi $^{(\mathbb{D}}$
}

${ }^{1}$ Department of Exercise Physiology, Central Tehran Branch, Islamic Azad University, Tehran, Iran

${ }^{2}$ Cellular and Molecular Research Center, Iran University of Medical Sciences, Tehran, Iran

${ }^{3}$ Departments of Microbiology, Karaj Branch, Islamic Azad University, Karaj, Iran

\begin{abstract}
Background: Diazinon is an organophosphate pesticide that is broadly applied to control insects which causes oxidative damages in hippocampus tissue. We aimed to examine whether resistance training and berberine supplementation can protect the hippocampus against berberine-induced neural toxicity.

Methods: Fifty-six male Wistar rats were assigned randomly into eight groups of seven including: Control (Ctrl), Sham (normal saline), T1 (diazinon + berberine chloride $(2 \mathrm{mg} / \mathrm{kg})+$ resistance training), T2 (diazinon + berberine chloride $[15 \mathrm{mg} / \mathrm{kg}]+$ resistance training), T3 (diazinon), T4 (diazinon +resistance training), T5 (diazinon + berberine chloride $[2 \mathrm{mg} / \mathrm{kg}]$ ), and T6 (diazinon + berberine chloride $[15 \mathrm{mg} / \mathrm{kg}]$ ). In the experimental groups, diazinon was intraperitoneally administered at a dose of $1.5 \mathrm{mg} / \mathrm{kg}$. In the training groups, rats were trained every three days for six weeks and 8-12 dynamic movements (repetitions) during each climb (six climbs for two sets). The expression of hippocampus PI3K and CDK genes and TrkB and ERK protein levels were evaluated in the brain of diazinon-treated rats.

Results: The protein expression of ERK and TrkB were increased following the treatment of diazinonintoxicated rats with berberine and resistance training $(P=0.001)$. The administration of berberine at a dose of $15 \mathrm{mg} / \mathrm{kg}$ in combination with resistance training significantly $(P=0.001)$ decreased the cell death rate in the hippocampus. Diazinon treatment caused extensive apoptosis in the hippocampus region of the rats' brain $(P=0.001)$. The gene expression of PI3K and CDK was significantly increased and the cell death rate significantly decreased $(P=0.001)$ in the hippocampus following the treatment of rats with berberine and resistance training.

Conclusion: Six weeks of resistance training in combination with berberine treatment significantly reduced apoptosis in the hippocampus region of diazinon-intoxicated rats. It seems the neuroprotection effects of berberine and resistance training are mediated by the stimulation of the expression of enzymes responsible for the antioxidant defense within neuronal cells.

Keywords: Neural toxicity, PI3K, CDK signaling pathway, Resistance training; Hippocampus
\end{abstract}

*Correspondence to Mohammad Ali Azarbayjani, Department of Exercise Physiology, Central Tehran Branch, Islamic Azad University, Tehran, Iran. Tel: +98-21- 22481622; Email: m_azarbayjani@iauctb. ac.ir

Published online December 30, 2020

Citation: Shakouri E, Azarbayjani MA, Jameie SB, Peeri M, Farhadi M. Berberine supplement and resistance training may ameliorate diazinon induced neural toxicity in rat hippocampus via the activation of the TrkB and ERK signaling pathway. Clin Neurosci J. 2021;8(1):14-21. doi:10.34172/icnj.2021.04.

\section{Introduction}

Diazinon (O, O-diethyl-O-[2-isopropyl-6-methylpyrimidin-yl] phosphorothioate) is an organophosphate insecticide commonly used to control insects in the agriculture and as a pesticide in domestic animals worldwide. ${ }^{1,2}$ Organophosphorus pesticides induce adverse effects on many organs such as the liver, pancreas, kidney, and brain..$^{3-5}$ The central nervous system (CNS) is mostly the main part of the human body which is susceptible to the toxic effects of organophosphate compounds. Several studies have investigated the effect of diazinon on different organs of the human body. ${ }^{6,7}$

These agents or their active metabolites inhibit acetylcholinesterase. This causes the accumulation of acetylcholine at cholinergic synapses leading to hyperstimulation of cholinergic receptors, particularly in the CNS. It is believed that the main target of the toxic effects of these components is the CNS. ${ }^{2,8}$ Several reports indicate that the accumulation of choline on neurons causes neuronal cell death in some brain regions such as the hippocampus and thalamus. ${ }^{9,10}$ Exposure to diazinon induces apoptosis in neural cells. ${ }^{11}$ Upon the exposure

(C) 2021 The Author(s). This is an open access article distributed under the terms of the Creative Commons Attribution License (http:// creativecommons.org/licenses/by/4.0/), which permits unrestricted use, distribution, and reproduction in any medium, provided the original work is properly cited. 
of neuronal cells to diazinon, they produce excessive amounts of free radicals that are highly reactive and unstable, causing oxidative damage to both tissues and cells. ${ }^{12}$ Additionally, the over-production of oxygen free radicals following the induction of oxidative stress, results in the increase in lipid peroxidation and DNA damage which could push the cells toward apoptosis. ${ }^{13}$ The toxic impact of diazinon on the CNS and signal transmission system could be mediated through the alteration of the expression of a group of neural growth factor genes including brain-derived neurotrophic factor (BDNF) which is a member of the neurotrophin superfamily responsible for the promotion of growth, development, and the survival of neuronal populations. Slotkin et al showed that exposure to organophosphates (chlorpyrifos and diazinon) reduces the expression of neurotrophic factors in neonatal rat brain region. ${ }^{14}$ Substantial evidence suggests an association between organophosphate insecticide exposure and neurobehavioral alterations. ${ }^{15}$ Using herbal supplement or performing regular physical activity with increasing antioxidant capacity and neurotropic factor reinforces neural cell in face of the toxic agent. Sonei and colleagues ${ }^{16}$ considered protective effects of Berberis vulgaris on diazinon-induced brain damage in young male mice. These researchers stated that administration of $200 \mathrm{mg} / \mathrm{kg} \mathrm{B}$. vulgaris extract with diazinon significantly decreased oxidative stress indices in all experiments. Their results indicated that $\mathrm{B}$. vulgaris extract has protective effects against lipid peroxidation of the cerebellum and cerebrum, and in regenerating acetylcholinesterase activity in the brain induced by diazinon.

Berberine is an isoquinoline-derived alkaloid and belongs to a Chinese medicinal herb with multiple pharmacological properties. Berberine exerts potent neuroprotective effects against many brain disorders, such as ischemia, Alzheimer's disease, and brain tumors. As it is a small molecule, it can cross the blood-brain barrier and exert its beneficial effects on the CNS. ${ }^{17-19}$ Consistently, previous studies reported the anti-inflammatory, antioxidant, anti-apoptotic and neuroprotective potentials of berberine ${ }^{20}$ It is stated that berberine could reduce apoptosis by upregulation of $\mathrm{p}$-Akt and $\mathrm{Bcl}-2$, and downregulation of Bax and cleaved caspase- $3 .{ }^{21}$

A growing body of evidence indicates that physical exercise is capable of attenuating neurological and psychiatric disorders through increasing neurotrophic factors and decreasing oxidative stress. ${ }^{22,23}$ Previous studies showed that exercise training enhanced brain antioxidant response. ${ }^{24}$ BDNF is a neurotropic factor within the central and peripheral nervous system, controlling neuronal development and differentiation. ${ }^{25}$ TrkB is expressed in the CNS and also peripheral nervous system and acts as a receptor for BDNF. TrkB is highly expressed in the CNS. Once BDNF binds to its cognate receptor, TrkB activates multiple signaling pathways, including phosphatidylinositol 3-kinase (PI3K), MAPK/ ERK, phospholipase $\mathrm{C}$, and protein kinase $\mathrm{C}$ cascades, and plays essential roles in cell proliferation, differentiation, and the survival of different cell types. ${ }^{26}$

Daily wheel-running exercise increases the expression of BDNF at protein and gene levels in the hippocampus. ${ }^{27,28}$ Moreover, during exercise, proteins and their metabolic derivatives secreted from peripheral muscles, such as cathepsin B and FNDC5/irisin, cross the blood brain barrier to mediate BDNF expression in the hippocampus and subsequent neurogenesis and memory improvement. ${ }^{29}$ Studies on animal models show greater improvement in acquisition and retention-based learning in hippocampus-dependent tasks following long-term exercise rather than shorter regimes of exercise. ${ }^{30,31}$ However, the study about resistance training with natural supplement on hippocampus signalling is limited. For that reason, in this study, the effect of berberine and resistance training is evaluated on the protection of the hippocampal tissue of rats against diazinon intoxication. Since intoxication of rats with diazinon has major impacts on neural cell death, it would be of great importance to determine the level of apoptosis induction and to seek novel therapeutic strategies. Therefore, we aimed to examine the combinatory effects of berberine and physical exercise on the amelioration of diazinon-induced neurotoxicity and measure the expression of ERK and TrkB proteins.

\section{Materials and Methods \\ Reagents}

The reagents used in the present study included diazinon (Sigma-Aldrich; St. Louis, MO, USA), cDNA synthesis kit (Fermentase, Germany), SYBR Green Premix 2X (Takara, Shiga, Japan), Qiazol (Qiazol lysis reagent, USA), RIPA buffer (Sigma, USA), protease inhibitor cocktail (Sigma, USA), polyacrylamide gel electrophoresis (Bio-Rad, USA), PVDF membrane (Sigma, USA), non-fat milk (Sigma, USA), Tween (Merck, Germany), Polyclonal rabbit anti-beta actin antibody (Abcam, UK), and DAB (3, 3'-diaminobenzidine) (DAKO, Germany).

\section{Animal Model and Drug Treatment}

In this study, 56 male Wistar rats (40-50 weeks of age), with a body weight of $250-300 \mathrm{~g}$, were selected at the laboratory animal research center of the Islamic Azad University, Central Tehran branch. Rats were housed in cages ( $\mathrm{n}=4$ per cage) measuring $30 \times 15 \times 15 \mathrm{~cm}$ under controlled conditions (ambient temperature of $22 \pm 2^{\circ} \mathrm{C}$, humidity $50 \pm 5$, and a 12:12 light/dark cycle) with adequate standard laboratory food and tap water ad libitum. The study was approved by the Animal Care and Use Committee at the Islamic Azad University, Central Tehran branch. Animals were divided into eight groups 
of seven rats: Healthy-Control (Ctrl), Sham (normal saline), T1(diazinon + berberine chloride $[2 \mathrm{mg} / \mathrm{kg}]+$ resistance training), T2 (diazinon + berberine chloride [15 mg/kg] + resistance training), T3 (diazinon), T4 (diazinon + resistance training), T5 (diazinon + berberine chloride $[2 \mathrm{mg} / \mathrm{kg}]$ ), and T6 (diazinon + berberine chloride [15 mg/kg]). Berberine chloride was purchased from Sigma (Sigma-Aldrich; St. Louis, MO, USA), and applied orally at two single doses of 2 and $15 \mathrm{mg} / \mathrm{kg}$ body weight for 6 weeks. Diazinon was purchased from Sigma (Sigma-Aldrich; St. Louis, MO, USA) and administered intraperitoneally at a dose of $1.5 \mathrm{mg} / \mathrm{kg}$ body weight.

Resistance Training

The training groups were trained to climb a ladder (100 cm long, $2 \mathrm{~cm}$ separating each rung, $80^{\circ}$ incline) with weights secured to the tail of rats. Each training session consisted of six climbs for two sets, and rats were submitted to make 8 to 12 dynamic movements per climb. The rest time between intervals was 60 seconds. The exercise program was performed 3 sessions per week which totally lasted for 4 weeks. Body weight was measured at the beginning of each weekly training. The weights secured to the tail of rats were daily adjusted to changes in each animal's body weight. The experiment began with tail weights equal to $10 \%$ of the rats' body weight, and gradually increased to $50 \%$ of the body weight at the end of the training period.

\section{Real-time PCR}

Total RNA was extracted from hippocampus applying Qiazol (Qiazol lysis reagent, USA) in a sterilized RNasefree tube. RNA purification and concentration were determined by a NanoDrop ND-100 spectrophotometer (Thermo Scientific, Waltham, MA, USA). cDNA was synthesized after RNA extraction by using the DNase I first strand synthesis system for qRT-PCR detection (Fermentase, Germany) in $20 \mu \mathrm{L}$ volume following the manufacturer's datasheet. Reaction mixture for quantitative RT-PCR amplification was prepared in a final working solution containing: $2 \mu \mathrm{L}$ of the cDNA synthesis reaction, $12.5 \mu \mathrm{L}$ AccuPrime SuperMix I (Fermentase, Germany), $0.2 \mu \mathrm{L}$ of each $100 \mu \mathrm{mol} / \mathrm{L}$ forward and reverse primer and $10.1 \mu \mathrm{L}$ DNA-RNase free water. Primer3 software was applied for primer design and then blasted in NCBI website. The used primers in the present research for quantitative RT-PCR are represented in Table 1.

For gene expression assessment during quantitative RT-PCR, $500 \mathrm{ng}$ of synthesized cDNA were used in a total volume of $25 \mu \mathrm{L}$ containing $12.5 \mu \mathrm{L}$ SYBR Green Premix 2X (Takara, Shiga, Japan) and 10 pM of forward and reverse primers. Thermocycling conditions were as follows: $95^{\circ} \mathrm{C}$ for 10 seconds followed by 40 cycles of denaturation at $94^{\circ} \mathrm{C}$ for 5 seconds, annealing and extension at $60^{\circ} \mathrm{C}$ for 34 seconds. We used the $\Delta \Delta \mathrm{CT}$ method for the determination of relative expression for PI3K and CDK genes. The Ct of the samples was compared with the $\mathrm{Ct}$ of the internal control (GAPDH). Real-time PCR was performed by the ABI (Applied Biosystems, USA) detection system. All reactions were done in duplicate. The specificity of PCR reaction was double-confirmed by electrophoresis and melting curve analysis (Figure 1).

\section{Western Blot Analysis}

To detect ERK and TrkB proteins, the western blot analysis was performed in homogenates of rat hippocampus. The hippocampus was homogenized in RIPA buffer (Sigma, USA) with a protease inhibitor cocktail (Sigma, USA) and centrifuged at $15000 \mathrm{rpm}$ at $4^{\circ} \mathrm{C}$ for 10 minutes. Then the protein content of the isolated supernatant was determined by the Lowry method, and then polyacrylamide gel electrophoresis (Bio-Rad, USA) was performed to protein separating. After electrophoresis, proteins were transferred onto polyvinylidene fluoride (PVDF) membrane. The PVDF membrane was blocked in TBS containing $0.1 \%$ Tween-20 and $5 \%$ non-fat milk (Sigma, USA) at $4^{\circ} \mathrm{C}$ overnight. After incubating with the primary antibody, the membrane was washed with PBS-Tween (TBST) and then incubated with secondary antibodies at room temperature for one hour.

Polyclonal rabbit anti-beta actin antibody was used as a loading control for western blot analysis. After washing, the membranes were visualized using DAB (3, 3'-diaminobenzidine) substrate until optimum color developed. The protein bands were then captured and analyzed using ImageJ software. All protein bands were normalized against $\beta$-actin.

\section{Statistical Analysis}

All data are presented as mean and standard deviation

Table 1. Sequences of Primers, Melting Temperature, and the Length of PCR Products

\begin{tabular}{lll}
\hline Official Name & Primer Sequences & Accession Number \\
\hline \multirow{2}{*}{ GAPDH } & F: 5'-AAGTTCAACGGCACAGTCAAGG -3' & NM_017008 \\
& R: 5'- CATACTCAGCACCAGCATCACC -3' & \\
PI3K & F:5'- TTAAACGCGAAGGCAACGA -3' & XM_008760659.2 \\
& R: 5'- CAGTCTCCTCCTGCTGTCGAT -3' & \\
CDK & F:5'- TTGAAAGGGAGGAAGAAGGAG $-3^{\prime}$ & XM_006256353.3 \\
& R:5'-ATGGACAGGAACACGAAGATGA -3' & 101 \\
\hline
\end{tabular}



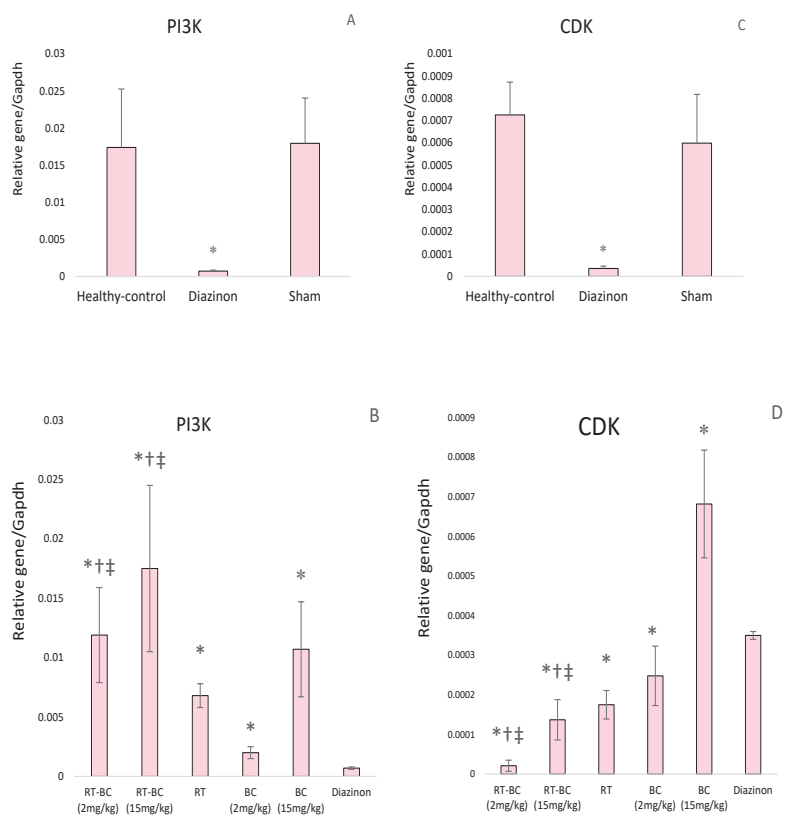

Figure 1. The Effect of Berberine on the Expression of PI3K And CDK Genes in Brain Tissue of Diazinon-Intoxicated Rats After Six Weeks of Treatment. The transcription level of each sample was normalized against GAPDH transcription level. The reactions were performed in six separate experiments. The errors reported represent mean $\pm \mathrm{SD}$. ${ }^{*}$ denote significant differences to diazinon group.t denote significant differences to RT group. $\neq$ denote significant differences to BC group RT-BC (2 $\mathrm{mg} / \mathrm{kg})$ : diazinon + berberine chloride $(2 \mathrm{mg} / \mathrm{kg})$ + resistance training, RT-BC(15 $\mathrm{mg} / \mathrm{kg})$ : diazinon + berberine chloride $(15 \mathrm{mg} / \mathrm{kg})+$ resistance training, TR: diazinon +resistance training, BC (2 mg/kg): diazinon + berberine chloride $(2 \mathrm{mg} / \mathrm{kg})$, BC $(15 \mathrm{mg} / \mathrm{kg})$ diazinon + berberine chloride $(15 \mathrm{mg} / \mathrm{kg})$, Control and Sham: normal saline. $n=8$ in each group.

(SD). Two-way analysis of variance (ANOVA) followed by Bonferroni post hoc test were used to compare significant differences between the groups. The data were analyzed by SPSS software, version 19 (SPSS Inc., Chicago, IL). The level of significance was set at $P<0.05$.

\section{Results}

\section{Effects of Berberine and Resistance Training on transcript Levels of (PI3K and CDK)}

$\mathrm{PI} 3 \mathrm{~K}$ gene expression in the diazinon control group was significantly lower than the healthy control $(P=0.001)$ and sham $(P=0.001)$ groups. There was no significant difference in the expression of this gene between the healthy control group and the Sham control group $(P=0.979)$ (Figure 1 , section A). Resistance training could significantly increase PI3K gene expression in the diazinon-poisoned group $(\mathrm{F}=38.48, P=0.001, \eta$ $=0.478)$. Berberine chloride intake also significantly increased PI3K gene expression in diazinon-poisoned rats $(\mathrm{F}=25.15, P=0.001, \eta=0.545)$. This increase was dose-dependent and the dose of $15 \mathrm{mg} / \mathrm{kg}$ of body weight could significantly increase the expression of this gene compared to the control group $(P=0.001)$.

Although the highest expression of PI3K gene was observed in the resistance training and $15 \mathrm{mg} / \mathrm{kg}$ berberine chloride group, the interaction of these two interventions on the expression of this gene was not statistically significant $(\mathrm{F}=0.852, P=0.434, \eta=0.039)$ (Figure 1, section $\mathrm{B})$. CDK gene expression also decreased significantly due to diazinon poisoning $(P=0.001)$. The sham group had no significant effect on the expression of this gene $(P=0.335)$ (Figure 2, section $C)$.

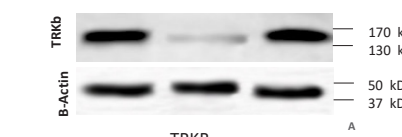

TRKB
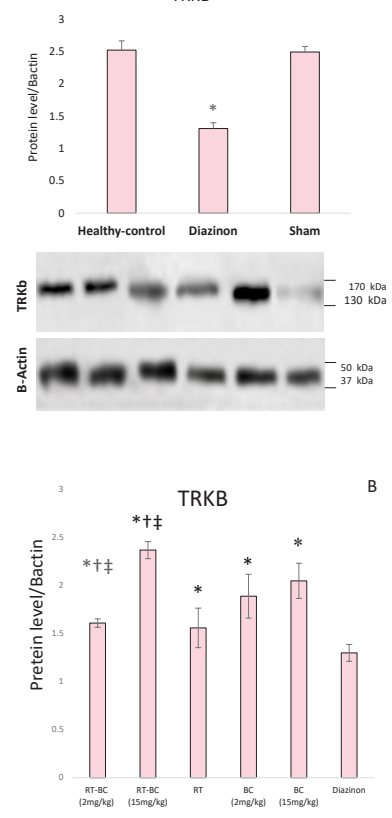

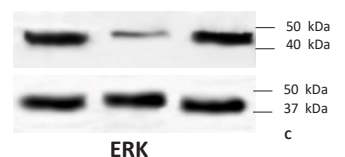

ERK
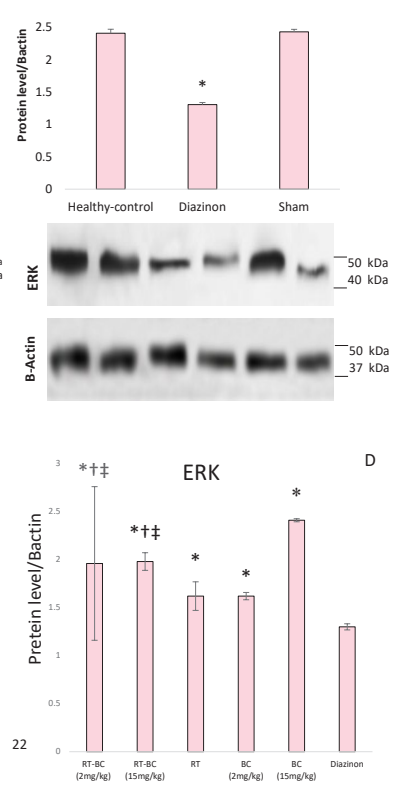

Figure 2. The Effect of Different Treatment Procedures Consisting of Diazinon, Berberine, and Resistance Training on the expression of ERK and TrkB Protein. Rats were intoxicated with $1.5 \mathrm{mg} /$ $\mathrm{kg}$ diazinon and then treated with (2 or $15 \mathrm{mg} / \mathrm{kg}$ ) berberine followed by six weeks of resistance training. Hippocampus tissues were subjected to SDS-PAGE followed by western blot analysis, as described in the materials and methods section of the manuscript, using a ) of ERK and TrkB antibodies. $\beta$-Actin was utilized as an internal control. Representative blots of three independent experiments with identical observations. Semiquantitative analysis of b) ERK and c) TrkB proteins expression between diazinon-intoxicated rats and normal rats. d) Semiquantitative analysis of ERK and TrkB protein expression in brain tissue of diazinon-intoxicated rats after 6 weeks treatment. The errors reported represent mean \pm SD. * denote significant differences to diazinon group.t denote significant differences to RT group.‡ denote significant differences to $\mathrm{BC}$ group RT-BC (2 $\mathrm{mg} / \mathrm{kg})$ : diazinon + berberine chloride $(2 \mathrm{mg} / \mathrm{kg})+$ resistance training, RT-BC (15 mg/kg): diazinon + berberine chloride (15 mg/ $\mathrm{kg})+$ resistance training, TR: diazinon +resistance training, $\mathrm{BC}(2$ $\mathrm{mg} / \mathrm{kg})$ : diazinon + berberine chloride $(2 \mathrm{mg} / \mathrm{kg}), \mathrm{BC}(15 \mathrm{mg} / \mathrm{kg})$ diazinon + berberine chloride $(15 \mathrm{mg} / \mathrm{kg})$, Control and Sham: normal saline. $\mathrm{n}=8$ in each group. 
Resistance training could significantly increase CDK gene expression in the poisoned group $(\mathrm{F}=110.84$, $P=0.001, \eta=0.725)$. Berberine chloride could increase the expression of this gene $(\mathrm{F}=93.95, P=0.001, \eta=0.817)$. However, the incremental effect of berberine at a dose of $15 \mathrm{mg} / \mathrm{kg}$ of body weight was significant $(P=0.001)$. The interaction of resistance training and berberine chloride on CDK gene expression was statistically significant ( $F$ $=97.96, P=0.001, \eta=0.823)$, so that resistance training and $15 \mathrm{mg}$ of berberine chloride enhanced its effect on increasing the CDK gene expression.

\section{Western Blot Analysis of ERK and TrkB Proteins}

TrKB protein expression in the diazinon control group was significantly lower than the healthy control $(P=0.001)$ and sham $(P=0.001)$ groups. No significant difference was observed between the healthy and sham control groups $(\mathrm{P}=0.855)$ (Figure 2, section $\mathrm{A})$.

Resistance training significantly increased $\mathrm{TrKB}$ protein expression $(\mathrm{F}=4.67, P=0.036, \eta=0.10)$. Berberine intake also had a significant increase in $\operatorname{TrKB}$ protein expression ( $\mathrm{F}=100.32, P=0.001, \eta=0.827)$. The increase of this protein in the $15 \mathrm{mg} / \mathrm{kg}$ body weight group was more than $2.5 \mathrm{mg}(P=0.001)$. The interaction of training and berberine also had a significant effect on $\operatorname{TrKB}(\mathrm{F}=17.80$, $P=0.001, \eta=0.459)$.

Resistance training and berberine, especially at a dose of $15 \mathrm{mg} / \mathrm{kg}$ body weight, enhanced the effect on TrKB protein expression (Figure 2, section B). Diazinon poisoning significantly reduced ERK protein expression $(\mathrm{P}=0.001)$. There was no significant difference in the expression of this protein between the healthy and sham control groups $(\mathrm{P}=1.000)$ (Figure 2, section $\mathrm{C}$ ). Resistance training significantly increased ERK protein expression $(\mathrm{F}=10.50, P=0.002, \eta=0.200)$. Berberine intake also had a significant increase in ERK protein expression $(\mathrm{F}=$ 321.02, $P=0.001, \eta=0.939)$. The rate of increase of this protein in the $15 \mathrm{mg} / \mathrm{kg}$ of body weight group was more than $2.5 \mathrm{mg}(P=0.001)$.

The interaction of training and berberine consumption also significantly increased the effect of ERK protein ( $F$ $=115.22, P=0.001, \eta=0.846)$. Resistance training and berberine intake, especially at $15 \mathrm{mg}$ dose, enhanced its incremental effect on ERK protein expression (Figure 2, section D).

\section{Discussion}

This study demonstrated that diazinon damages to several organs through the induction of severe histopathological lesions in the liver, kidney, and brain. ${ }^{2-33}$ Our results also show that consumption of diazinon gavage in rats significantly decreases PI3K, CKD1, ERK and TRKB in the brain tissue. In line with this study, Maroni and colleagues reported that diazinon could cause irreversible damages to the nervous system via inhibitory effects on the acetylcholinesterase activity. ${ }^{34}$ Also, Boussabbeh et al showed that diazinon caused cell death and DNA damage in HCT116 cells via generation of free radicals. ${ }^{5}$ It seems that free radicals which are induced by the exposure of neuronal cells to diazinon are able to initiate the process of programmed cell death. ${ }^{5,35,36}$ In other tissues, Wang and colleagues showed that cytotoxicity and DNA damage were caused by diazinon exposure through inhibiting the PI3K-AKT pathway in porcine ovarian granulosa cells. ${ }^{37}$ Therefore, it seems that in the brain tissue, diazinon with increasing oxidative stress affected PI3K, CKD1, ERK and TRKB and reduction in these factors increases susceptibility of the brain to degenerative disease. Using herbal supplements can reduce the destructive effects of the ROS. Moreover, berberine has neuroprotective effects by up-regulating pAkt, pGSK and pCREB, and downregulating $\mathrm{NF}-\kappa \mathrm{B}$ expression. ${ }^{38}$

In this study, we focused on applying berberine and resistance training as novel combinatory treatment regimens for rats intoxicated with diazinon. Our results highlighted that PI3K, CKD1, ERK and TRKB were highest in the diazinon-treated group while the administration of berberine ( 15 and $2 \mathrm{mg} / \mathrm{kg}$ ) mitigated the rate of neurological damage in the brain of rats. Oxidative stress and mitochondrial dysfunction are associated with neurodegenerative diseases. In line with results of our study, growing evidence indicates that berberine has a beneficial effect on the treatment of neurodegenerative diseases due to its antioxidant and antiapoptotic properties. ${ }^{39-41}$ It is stated that, berberine also up-regulates Bcl-2, downregulates Bax and caspase- 3 in MPTP-induced PD mouse model. ${ }^{42}$ In our study, we used diazinon that could induce and increase ROS and cause neurotoxicity. However, in line with other studies, it seems that berberine with reducing oxidative damage affects upregulating PI3K, CKD1, ERK and TRKB. In other words, resistance training can improve neuroprotection with reducing ROS. Also, resistance training can separately upregulate synthesis factor in cells such as AKT and PI3K. ${ }^{43,44}$

In addition, we evaluated the expression of $\operatorname{TrkB}$ and ERK proteins following the administration of berberine and resistance training in intoxicated rats to investigate neurogenesis in the hippocampus region of rats' brain. Our data showed that TrkB and ERK levels significantly increased after the treatment with berberine, and such an increase in the levels of these two proteins was further highlighted when diazinon-intoxicated rats were treated with the combination of both berberine and physical exercise, suggesting that both have potentials to induce neurogenesis in the brain of animals. A number of studies showed that in in vitro models of the brain ischemia, berberine decreases cell death through the Akt/GSK3 $\beta$ / ERK1/2 survival/apoptotic signaling pathway, and it could halt the activity of the JNK pathway and caspase- $3 .{ }^{45}$ 
Consistent with our study, Yang and colleagues showed that berberine could exert neuroprotective effects thereby reducing the rate of apoptosis via the BDNF-TrkBPI3K/Akt signaling pathway on rats which undergo cerebral ischemia. ${ }^{20}$ In this context, some studies reported that berberine could upregulate the expression of BDNF in the hippocampus area of the brain. ${ }^{46}$ It has been indicated that $\mathrm{BDNF} /$ TrkB dysregulation leads to cell proliferation changes, as well as degenerative and behavioral alterations in the brain. ${ }^{47}$ So, we suggest that berberine, in combination with resistance training, is capable of inducing neurogenesis by upregulation of both ERK and TrkB. A considerable body of evidence shows the beneficial impact of exercise on different areas of the brain such as the hippocampus which resulted in progress in the understanding of the exercise on a number of regions including cognitive function and neurobiology of learning and memory. ${ }^{48}$ Another study showed that BDNF was significantly increased in response to physical exercise, and parallel with the intensity of exercise, the expression rate of BDNF would be elevated. ${ }^{49}$

In summary, berberine treatment and resistance training alleviate neurological impairments in the hippocampal region of the brain of diazinon-intoxicated rats, and such protection is thought to be mediated by the reduction in neuronal apoptosis. Therefore, our study provides tantalizing evidence for the future clinical use of berberine in combination with exercise for patients who were unwantedly exposed to diazinon. Various reports have revealed that the reduced number of apoptotic cells may be due to the potent antioxidant activity and neuroprotective potentials of berberine and resistance training. Hence, the combination of resistance exercise and berberine could be recommended for those individuals affected by diazinon toxicity.

\section{Conclusion}

Based on the results mentioned above, it could be implied that diazinon caused cell death via apoptosis in the rats' brain. Additionally, berberine at a concentration of $15 \mathrm{mg}$ / $\mathrm{kg}$ could significantly reduce diazinon-induced cell death. Although resistance training could alone reduce the rate of cell death, the combination of resistance training and berberine had significant impacts on the protection of neuronal cells, which ultimately resulted in the upregulation of ERK, TrkB proteins and CDK1 and PI3K genes levels. It is suggested that further studies should be done by applying other sorts of exercise and berberine on neurogenic pathways and investigate oxidative stress levels induced by an increase in toxins in the brain tissue.

\section{Conflict of Interest}

None.

\section{Acknowledgments}

This research was supported by the Islamic Azad University, Central
Tehran branch.

\section{Authors' Contribution}

MA, SBJ ,MP and MF designed and directed the project. ES performed the experiments and wrote the article draft. All authors discussed the results and commented on the manuscript.

\section{Funding/Support}

The present research has supported the Neuroscience Research Center (NRC) of the Iran University of Medical Science and Islamic Azad University, Central Tehran Branch.

\section{Ethical Statement}

All steps of this study were approved by the Animal Ethics Committee, based on the Research Council of the Exercise Physiology, Islamic Azad University, Central Tehran Branch, Tehran, Iran

\section{References}

1. Timcheh Hariri A, Moallem SA, Mahmoudi M, Hosseinzadeh $H$. The effect of crocin and safranal, constituents of saffron, against subacute effect of diazinon on hematological and genotoxicity indices in rats. Phytomedicine. 2011;18(6):499504. doi: 10.1016/j.phymed.2010.10.001.

2. Razavi BM, Hosseinzadeh $H$, Movassaghi AR, Imenshahidi $M$, Abnous K. Protective effect of crocin on diazinon induced cardiotoxicity in rats in subchronic exposure. Chem Biol Interact. 2013;203(3):547-55. doi: 10.1016/j. cbi.2013.03.010.

3. Drufovka K, Danevčič T, Trebše P, Stopar D. Microorganisms trigger chemical degradation of diazinon. Int Biodeterior Biodegradation. 2008;62(3):293-6. doi: 10.1016/j. ibiod.2008.02.003.

4. Kalender S, Ogutcu A, Uzunhisarcikli M, Açikgoz F, Durak $D$, Ulusoy $Y$, et al. Diazinon-induced hepatotoxicity and protective effect of vitamin $\mathrm{E}$ on some biochemical indices and ultrastructural changes. Toxicology. 2005;211(3):197206. doi: 10.1016/j.tox.2005.03.007.

5. Boussabbeh M, Ben Salem I, Hamdi M, Ben Fradj S, AbidEssefi S, Bacha H. Diazinon, an organophosphate pesticide, induces oxidative stress and genotoxicity in cells deriving from large intestine. Environ Sci Pollut Res Int. 2016;23(3):2882-9. doi: 10.1007/s11356-015-5519-y.

6. Ghasemi S, Shabestani Monfared A, Zabihi E, Khoshbin Khoshnazar A, Asadi J, Abedian Z, et al. Changes in the Radiation Toxicity of Human Lymphoblastic T-cell Line (Jurkat) by a Common Pesticide: Diazinon. J Biomed Phys Eng. 2020;10(2):147-54. doi: 10.31661/jbpe.v0i0.715.

7. Abdel-Daim MM, Abushouk Al, Bahbah El, Bungău SG, Alyousif MS, Aleya L, et al. Fucoidan protects against subacute diazinon-induced oxidative damage in cardiac, hepatic, and renal tissues. Environ Sci Pollut Res Int. 2020;27(11):1155464. doi: 10.1007/s11356-020-07711-w.

8. Rashedinia $M$, Hosseinzadeh $H$, Imenshahidi $M$, Lari $P_{\text {, }}$ Razavi BM, Abnous K. Effect of exposure to diazinon on adult rat's brain. Toxicol Ind Health. 2016;32(4):714-20. doi: 10.1177/0748233713504806.

9. Čolović MB, Vasić VM, Avramović NS, Gajić MM, Djurić DM, Krstić DZ. In vitro evaluation of neurotoxicity potential and oxidative stress responses of diazinon and its degradation products in rat brain synaptosomes. Toxicol Lett. 2015;233(1):29-37. doi: 10.1016/j.toxlet.2015.01.003. 
10. Chen Y. Organophosphate-induced brain damage: mechanisms, neuropsychiatric and neurological consequences, and potential therapeutic strategies. Neurotoxicology. 2012;33(3):391-400. doi: 10.1016/j. neuro.2012.03.011.

11. Aluigi MG, Guida C, Falugi C. Apoptosis as a specific biomarker of diazinon toxicity in NTera2-D1 cells. Chem Biol Interact. 2010;187(1-3):299-303. doi: 10.1016/j. cbi.2010.03.031.

12. Kanakis CD, Tarantilis PA, Pappas C, Bariyanga J, TajmirRiahi HA, Polissiou MG. An overview of structural features of DNA and RNA complexes with saffron compounds: Models and antioxidant activity. J Photochem Photobiol B. 2009;95(3):204-12. doi: 10.1016/j.jphotobiol.2009.03.006.

13. Cakici O, Akat E. Effects of oral exposure to diazinon on mice liver and kidney tissues: biometric analyses of histopathologic changes. Anal Quant Cytopathol Histpathol. 2013;35(1):7-16.

14. Slotkin TA, Seidler FJ, Fumagalli F. Exposure to organophosphates reduces the expression of neurotrophic factors in neonatal rat brain regions: similarities and differences in the effects of chlorpyrifos and diazinon on the fibroblast growth factor superfamily. Environ Health Perspect. 2007;115(6):909-16. doi: 10.1289/ehp.9901.

15. Goldman L. Childhood Pesticide Poisoning: Information for Advocacy and Action. Geneva, Switzerland: United Nations Environment Programme (UNEP) and WHO, 2004.

16. Sonei A, Fazelipour S, Kanaani L, Jahromy MH. Protective Effects of Berberis vulgaris on Diazinon-Induced Brain Damage in Young Male Mice. Prev Nutr Food Sci. 2020;25(1):65-70. doi:10.3746/pnf.2020.25.1.65.

17. Yoo KY, Hwang IK, Lim BO, Kang TC, Kim DW, Kim SM, et al. Berberry extract reduces neuronal damage and N-MethylD-aspartate receptor 1 immunoreactivity in the gerbil hippocampus after transient forebrain ischemia. Biol Pharm Bull. 2006;29(4):623-8. doi: 10.1248/bpb.29.623.

18. Zhu F, Qian C. Berberine chloride can ameliorate the spatial memory impairment and increase the expression of interleukin-1beta and inducible nitric oxide synthase in the rat model of Alzheimer's disease. BMC Neurosci. 2006;7:78. doi: 10.1186/1471-2202-7-78.

19. Eom KS, Hong JM, Youn MJ, So HS, Park R, Kim JM, et al. Berberine induces G1 arrest and apoptosis in human glioblastoma T98G cells through mitochondrial/caspases pathway. Biol Pharm Bull. 2008;31(4):558-62. doi: 10.1248/ bpb.31.558.

20. Yang J, Yan H, Li S, Zhang M. Berberine Ameliorates MCAO Induced Cerebral Ischemia/Reperfusion Injury via Activation of the BDNF-TrkB-PI3K/Akt Signaling Pathway. Neurochem Res. 2018;43(3):702-10. doi: 10.1007/s11064-018-2472-4.

21. Li W, Liu Y, Wang B, Luo Y, Hu N, Chen D, et al. Protective effect of berberine against oxidative stress-induced apoptosis in rat bone marrow-derived mesenchymal stem cells. Exp Ther Med. 2016;12(6):4041-8. doi: 10.3892/etm.2016.3866.

22. Cotman CW, Engesser-Cesar C. Exercise enhances and protects brain function. Exerc Sport Sci Rev. 2002;30(2):75-9. doi: 10.1097/00003677-200204000-00006

23. Cotman CW, Berchtold NC. Exercise: a behavioral intervention to enhance brain health and plasticity. Trends Neurosci. 2002;25(6):295-301. doi: 10.1016/s0166-2236(02)02143-4.

24. Camiletti-Moirón D, Aparicio VA, Aranda P, Radak Z. Does exercise reduce brain oxidative stress? a systematic review. Scand J Med Sci Sports. 2013;23(4):e202-12. doi: 10.1111/ sms. 12065.

25. Fischer M, Wille G, Klien S, Shanib H, Holle D, Gaul C, et al. Brain-derived neurotrophic factor in primary headaches. J Headache Pain. 2012;13(6):469-75. doi: 10.1007/s10194012-0454-5.

26. Huang EJ, Reichardt LF. Trk receptors: roles in neuronal signal transduction. Annu Rev Biochem. 2003;72:609-42. doi: 10.1146/annurev.biochem.72.121801.161629.

27. Neeper SA, Gómez-Pinilla F, Choi J, Cotman CW. Physical activity increases mRNA for brain-derived neurotrophic factor and nerve growth factor in rat brain. Brain Res. 1996;726(12):49-56.

28. Berchtold NC, Chinn G, Chou M, Kesslak JP, Cotman CW. Exercise primes a molecular memory for brain-derived neurotrophic factor protein induction in the rat hippocampus. Neuroscience. 2005;133(3):853-61. doi: 10.1016/j. neuroscience.2005.03.026.

29. Moon HY, Becke A, Berron D, Becker B, Sah N, Benoni G, et al. Running-induced systemic cathepsin B secretion is associated with memory function. Cell Metab. 2016;24(2):332-40. doi: 10.1016/j.cmet.2016.05.025.

30. Ploeger HE, Takken T, de Greef MH, Timmons BW. The effects of acute and chronic exercise on inflammatory markers in children and adults with a chronic inflammatory disease: a systematic review. Exerc Immunol Rev. 2009;15:6-41.

31. Handschin C, Spiegelman BM. The role of exercise and PGC1alpha in inflammation and chronic disease. Nature. 2008;454(7203):463-9. doi: 10.1038/nature07206.

32. Shah MD, Iqbal M. Diazinon-induced oxidative stress and renal dysfunction in rats. Food Chem Toxicol. 2010;48(12):334553. doi: 10.1016/j.fct.2010.09.003.

33. Yehia MA, El-Banna SG, Okab AB. Diazinon toxicity affects histophysiological and biochemical parameters in rabbits. Exp Toxicol Pathol. 2007;59(3-4):215-25. doi: 10.1016/j. etp.2007.09.003.

34. Maroni M, Catenacci G, Galli D, Cavallo D, Ravazzani G. Biological monitoring of human exposure to acephate. Arch Environ Contam Toxicol. 1990;19(5):782-8. doi: 10.1007/ bf01183993.

35. Kamanyire R, Karalliedde L. Organophosphate toxicity and occupational exposure. Occup Med (Lond). 2004;54(2):6975. doi: 10.1093/occmed/kqh018.

36. Gokcimen A, Gulle K, Demirin H, Bayram D, Kocak A, Altuntas I. Effects of diazinon at different doses on rat liver and pancreas tissues. Pestic Biochem Physiol. 2007;87(2):103-8. doi: 10.1016/j.pestbp.2006.06.011.

37. Wang W, Luo SM, Ma JY, Shen W, Yin S. Cytotoxicity and DNA damage caused from diazinon exposure by inhibiting the PI3K-AKT pathway in porcine ovarian granulosa cells. J Agric Food Chem. 2019;67(1):19-31. doi: 10.1021/acs. jafc.8b05194.

38. Zhang X, Zhang X, Wang C, Li Y, Dong L, Cui L, et al. Neuroprotection of early and short-time applying berberine in the acute phase of cerebral ischemia: up-regulated pAkt, pGSK and pCREB, down-regulated NF-kB expression, ameliorated BBB permeability. Brain Res. 2012;1459:61-70. doi: 10.1016/j.brainres.2012.03.065.

39. Maleki SN, Aboutaleb N, Souri F. Berberine confers neuroprotection in coping with focal cerebral ischemia by targeting inflammatory cytokines. J Chem Neuroanat. 2018;87:54-9. doi: 10.1016/j.jchemneu.2017.04.008.

40. Hussien HM, Abd-Elmegied A, Ghareeb DA, Hafez HS, 
Ahmed HEA, El-Moneam NA. Neuroprotective effect of berberine against environmental heavy metals-induced neurotoxicity and Alzheimer's-like disease in rats. Food Chem Toxicol. 2018;111:432-44. doi: 10.1016/j.fct.2017.11.025.

41. Lotfi Aski M, Rezvani ME, Khaksari M, Hafizi Z, Pirmoradi Z, Niknazar S, et al. Neuroprotective effect of berberine chloride on cognitive impairment and hippocampal damage in experimental model of vascular dementia. Iran J Basic Med Sci. 2018;21(1):53-8. doi: 10.22038/ijbms.2017.23195.5865.

42. Deng H, Jia Y, Pan D, Ma Z. Berberine alleviates rotenoneinduced cytotoxicity by antioxidation and activation of $\mathrm{PI} 3 \mathrm{~K} /$ Akt signaling pathway in SH-SY5Y cells. Neuroreport. 2020;31(1):41-7. doi: 10.1097/wnr.0000000000001365.

43. Ribeiro AS, Deminice R, Schoenfeld BJ, Tomeleri CM, Padilha $\mathrm{CS}$, Venturini $\mathrm{D}$, et al. Effect of resistance training systems on oxidative stress in older women. Int J Sport Nutr Exerc Metab. 2017;27(5):439-47. doi: 10.1123/ijsnem.2016-0322.

44. Chanpakdee C, Viboolvorakul S, Patumraj S. Exercise training improves age-related changes in cerebral capillary vascularity through the upregulation of PI3K/Akt signaling. Chula Med J. 2019;63(4):229-38.

45. Simões Pires EN, Frozza RL, Hoppe JB, de Melo Menezes B,
Salbego CG. Berberine was neuroprotective against an in vitro model of brain ischemia: survival and apoptosis pathways involved. Brain Res. 2014;1557:26-33. doi: 10.1016/j. brainres.2014.02.021.

46. Shen JD, Ma LG, Hu CY, Pei YY, Jin SL, Fang XY, et al. Berberine up-regulates the BDNF expression in hippocampus and attenuates corticosterone-induced depressive-like behavior in mice. Neurosci Lett. 2016;614:77-82. doi: 10.1016/j. neulet.2016.01.002.

47. Gupta VK, You Y, Gupta VB, Klistorner A, Graham SL. TrkB receptor signalling: implications in neurodegenerative, psychiatric and proliferative disorders. Int J Mol Sci. 2013;14(5):10122-42. doi: 10.3390/ijms140510122.

48. Morgan JA, Corrigan F, Baune BT. Effects of physical exercise on central nervous system functions: a review of brain region specific adaptations. J Mol Psychiatry. 2015;3(1):3. doi: 10.1186/s40303-015-0010-8.

49. Ferris LT, Williams JS, Shen CL. The effect of acute exercise on serum brain-derived neurotrophic factor levels and cognitive function. Med Sci Sports Exerc. 2007;39(4):728-34. doi: 10.1249/mss.0b013e31802f04c7. 